\title{
Socioeconomic burden of sugar-sweetened beverages consumption in Korea
}

\author{
Jee-Seon Shim ${ }^{1,2}$, Nam Hoon Kang ${ }^{3}$, Jung Sug Lee ${ }^{4}$, Ki Nam Kim ${ }^{5}$, Hae Kyung Chung ${ }^{6}$, Hae Rang Chung ${ }^{7}$, Hung-Ju Kim ${ }^{8}$, \\ Yoon-Sook $\mathrm{Ahn}^{9}$ and Moon-Jeong Chang ${ }^{4 \S}$ \\ ${ }^{1}$ Department of Preventive Medicine, Yonsei University College of Medicine, Seoul 03722, Korea \\ ${ }^{2}$ Cardiovascular and Metabolic Diseases Etiology Research Center, Yonsei University College of Medicine, Seoul 03722, Korea \\ ${ }^{3}$ Department of Economics, Hanshin University, Osan 18101, Korea \\ ${ }^{4}$ Department of Food and Nutrition, Kookmin University, 77 Jeongeung-ro, Seongbuk-gu, Seoul 02707, Korea \\ ${ }^{5}$ Department of Food and Nutrition, Daejeon University, Daejeon 34520, Korea \\ ${ }^{6}$ Department of Food and Nutrition, Hoseo University, Asan 31499, Korea \\ ${ }^{7}$ Nutrition for the future (Inc), Seoul 08708, Korea \\ ${ }^{8}$ Department of Social Welfare, Wonkang University, Iksan 54538, Korea \\ ${ }^{9}$ Research Center of Social Economic, Wonkang University, Iksan 54538, Korea
}

BACKGROUND/OBJECTIVES: Excessive sugar consumption may increase the risk for development of several diseases. Although average dietary sugar intake of Koreans is within the recommended level, an increasing trend has been found in all age groups. This study aimed to evaluate the population attributable fractions (PAF) to dietary sugar for disease and death in Korea, and to estimate the socioeconomic effects of a reduction in dietary sugar.

MATERIALS/METHODS: The prevalence of sugar-sweetened beverages (SSB) overconsumption ( $\geq 20 \mathrm{~g}$ of sugar from beverages) was analyzed using the Korean National Health and Nutrition Examination Survey 2015. Disease-specific relative risks of excessive SSB consumption were obtained through reviewing previous studies. Using the prevalence of SSB overconsumption and each relative risk, PAFs for morbidity and mortality were calculated. Socioeconomic costs of diseases and death attributable to SSB overconsumption were estimated by using representative data on national medical expenditures, health insurance statistics, employment information, and previous reports.

RESULTS: Disease-specific PAF to SSB consumption ranged from $3.11 \%$ for stroke to $9.05 \%$ for obesity and dental caries, respectively. Costs from disease caused by SSB overconsumption was estimated at 594 billion won in 2015. About 39 billion won was estimated to be from SSB consumption-related deaths, and a total of 633 billion won was predicted to have been saved through preventing SSB overconsumption.

CONCLUSIONS: Sugars overconsumption causes considerable public burdens, although the cost estimates do not include any informal expenditure. Information on these socioeconomic effects helps both health professionals and policy makers to create and to implement programs for reducing sugar consumption.

Nutrition Research and Practice 2019;13(2):134-140; https://doi.org/10.4162/nrp.2019.13.2.134; pISSN 1976-1457 elSSN 2005-6168

Keywords: Dietary sugars, sugar-sweetened beverages, public health, costs

\section{INTRODUCTION}

Excessive consumption of dietary sugars is known to raise the risk for development of non-communicable diseases [1-6]. The World Health Organization (WHO) has recommended a reduced intake of free sugar to less than $10 \%$ of total energy (TE) intake [7]. Government and health organizations worldwide have set up their own guidelines for sugar intake [8], and have been pursuing various public health policies for reducing dietary sugar consumption, such as formulating a sugarsweetened beverage (SSB) excise tax $[9,10]$, developing an environment for reducing sugar consumption [11,12], and introducing programs to change dietary behavior [13-15].

According to a recent nationwide study [16], the average sugar intake of Koreans is lower than that of other countries $[17,18]$ and remains under the recommended level of the Korean Nutrition Society (KNS, 10 to 20\% TE) [19], and by the Ministry of Food and Drug Safety (MFDS, less than 10\% TE from processed foods) [20]. However, even in Korea, a public concern about dietary sugar has increased on account of the following reasons: youth sugar consumption has already exceeded the recommended level, processed products consumption has been

\footnotetext{
This study was supported by a grant (17162MFDS083) from the Ministry of Food and Drug Safety in 2017.

${ }^{\S}$ Corresponding Author: Moon-Jeong, Chang, Tel. 82-2-910-4776, Fax. 82-2-910-5249. E-mail. cmoon@kookmin.ac.kr

Received: July 31, 2018, Revised: August 15, 2018, Accepted: October 24, 2018

This is an Open Access article distributed under the terms of the Creative Commons Attribution Non-Commercial License (http://creativecommons.org/licenses/by-nc/3.0/) which permits unrestricted non-commercial use, distribution, and reproduction in any medium, provided the original work is properly cited.
} 
steadily on the rise, and an increased dietary sugar consumption trend has been found in all age groups [16,21]. In 2016, the Korea government announced the first preventive management action plan for sugar reduction [20], Meanwhile, academia and government have made efforts to improve public awareness and dietary habits, create a social environment for reducing sugar consumption, and developed a database on the content of sugar in food and conducted research for investigating the relationship of dietary sugar on diseases.

Public health promotion programs need human and material resources, but available resources are limited. Thus, in order to allocate limited resources for the total population, a consortium of government, business, and academia have estimated the socioeconomic burden of various health problems. The population attributable fraction (PAF) is the fraction of diseases attributable to risk factor exposure, that is, the proportion of diseases that could be prevented by eliminating unhealthy risk factors. This information helps policy makers prioritize among numerous health problems. However, no studies exist that estimate the potential influence and socioeconomic burden of dietary sugar consumption of the Korean population on disease incidence and health.

This study aimed to evaluate the PAF as related to dietary sugar consumption on the incidence of disease and death in Korea, and estimate the socioeconomic effects of dietary sugar reduction, providing scientific evidence for health professionals and policy makers.

\section{MATERIALS AND METHODS}

\section{SSB consumption}

Dietary sugar consumption was assessed using one day 24-hr recall data of the Korean National Health and Nutrition Examination Survey 2015 and the database for the total sugar content of foods from the MFDS [21]. Sugar consumption from beverages was calculated by summing all amount of sugar consumed from all beverages (e.g. soft drinks, tea, coffee, chocolate milk, yogurt, etc.) except white milk. The reason we excluded white milk was as follows. The dietary sugars we consume generally come from natural sugars present in foods and sugars that are added to foods and beverages during processing or cooking. Harmful effects of dietary sugars were only found when added sugars (or products rich in added sugars) were excessively consumed [7]. Thus, dietary advice on sugars mainly focuses on the added (or free) sugars. Among dairy foods, although it passes through some food manufacturing processes, white milk only contains natural sugars (lactose and galactose), whereas other milk beverages, such as flavored milk and yoghurt drinks, contain a considerable amount of added sugars. Thus, we tried to assess the dietary sugar consumption from all beverages except for white milk.

In this study, we defined consuming $\geq 20 \mathrm{~g}$ of sugar from beverages as SSB overconsumption ( $\geq$ one serving of sugary drinks). This amount is similar to the content in one serving $(200 \mathrm{~mL})$ of sugary drinks [21].

Relative risks of SSB overconsumption and population attributable fractions to SSB overconsumption
Diseases influenced by excessive sugar intake and diseasespecific relative risks of SSB consumption were obtained from previous studies [2-6,22-27]. Systematic review articles were preferred, however, narrative and individual original articles were also referenced if meta-analysis studies were not available.

The PAFs for each disease were calculated using the prevalence of SSB overconsumption and disease-specific relative risks, according to Levin's formula [28], which means the fraction of diseases attributable to SSB overconsumption. When the SSB overconsumption was prevented, morbidity and mortality related to sugar consumption were expected to be avoided.

The numbers of patients with SSB overconsumption-caused disease were estimated using the disease-specific PAF and the total number of patients with each disease from the 2015 National Health Insurance Statistics 2015 [29]. The PAF of death and the number of diminished deaths for adults aged 20 years or older were estimated using the PAF of sex-, age-(20-44 years, 45-64 years, and $\geq 65$ years), and cause-specific deaths reported by the Global Burden of Diseases Nutrition and Chronic Diseases Expert Group [1] and the total number of sex-, age group-, and cause-specific deaths reported by Statistics Korea in 2015 [30]. The causes of death were limited to specific diseases associated with sugar consumption, including type 2 diabetes mellitus, cardiovascular diseases, and specific-site cancers (esophagus, gallbladder, pancreas, colon, uterus, breast, or kidney).

\section{Socioeconomic burden due to SSB overconsumption}

If the magnitude of diseases in the population decreases along with preventing SSB overconsumption, costs associated with the treatment of the diseases are saved. Socioeconomic costs also could be saved in accordance with a decrease of SSB consumption-affected deaths. This burden was evaluated by cost savings when excessive SSB consumption was assumed to be prevented. This approach are applied in investigating the cost-benefits of the risk factor (e.g. smoking, excessive dietary sodium intake) prevention policy [31,32]. The costs consist of direct medical care costs and non-medical care costs (e.g. transportation, caregiver expenses), and indirect costs due to labor loss. All costs were estimated in 2015 prices.

\section{Cost savings due to reduced patients}

Medical care cost varies by the type of treatment, thus the cost savings were evaluated at the outpatient and inpatient levels, respectively. In outpatient treatment settings, medical cost savings were estimated by multiplying the number of reduced outpatients by the average annual outpatient medical expense per patient. The average annual outpatient medical expenses per patient were applied after calculating the amount using the annual aggregate outpatient medical expenses and the total number of outpatients reported by the National Health Insurance Service [29]. While the total medical fee consists of a co-payment (paid by the patient), the insurance benefit (paid by NHIS), and a non-insured co-payment (paid by the patient), the medical expenses in the statistical yearbook [29] refers only to the sum of the co-payment paid by the patient and the insurance benefits. In order to assume the medical expense, including the non-insured co-payment paid by the patient, the rate of the non-benefit co-payment paid by the patient [33] 
was applied to estimate the amount of medical care cost savings.

Among outpatients, savings in the transportation costs were estimated by multiplying the number of reduced outpatients and the number of medical institution visits per outpatient by transportation costs per visit for outpatient treatment. Among inpatients, savings were calculated by multiplying the number of reduced inpatients by the annual transportation costs for hospitalization treatments per inpatient. The transportation costs in 2015 were assumed by reflecting the consumer price index as the costs presented in the KNHANES 2005 report [34]. Reduction in the number of patients can lead to savings in caregiver costs. The savings in caregiver costs were estimated using the number of reduced inpatients, the number of hospitalized days per inpatient, and an average daily wage of the caregiver. The number of hospitalized days was calculated using the total number of inpatients and the annual aggregate number of hospitalized days in 2015 [29]. The consumer price index was reflected in the calculation of the daily wage of the caregiver in 2015 from the wage reported in 2005 [34].

Besides the aforementioned direct cost savings, reduced numbers of patients would also bring about reduced labor losses along with decreased medical institution visits. Indirect cost savings from reduced labor losses were estimated using the number of reduced patients, the number of medical institution visits per patient [29], sex- and age-specific average daily wages, and employment rates [35,36]. In the case of inpatient treatment, the number of hospitalized days was treated the same as the number of medical institution visits, although one visit for outpatient treatment was considered as a labor loss for half a day.

Cost savings due to reduced deaths

If patients die prior to average life expectancy, future expected income for the rest of their life would be lost. Cost savings from reduced deaths were estimated using the number of sex-, age-, and cause-specific deaths as well as sex- and age-specific future expected income. The future expected income was calculated by summing sex and age-specific annual expected income from the age at death to their average life expectancy, and each annual expected income was calculated using sex and age-specific annual employee income and sex and age-specific employment rates $[35,36]$. For patients between 70-79 years of age, the employment rates and annual employee income were treated as half of that of individuals aged $\geq 65$ years. Patients aged 80 years or older were considered unemployed and unwaged.

\section{Ethics}

In Korea, national studies, such as the KNHANES, which national organizations carry out to improve public welfare, are allowed to be conducted without the approval of the Institutional Review Board (IRB) on the basis of the Bioethics and Safety Act [37]. Thus, the protocol of KNHANES 2015 was exempted from the IRB approval requirement. Written informed consent was provided by all participants.

\section{RESULTS}

\section{Prevalence of SSB consumption}

Average daily intake of total dietary sugars was $76.9 \mathrm{~g}(15.1 \%$ TE) and $45.9 \mathrm{~g}$ of sugars (8.7\% TE) were consumed from processed food except for white milk (data not shown).

Although the average consumption was under the recommended level by the MFDS [38] and the KNS [19], one in three Koreans (33.2\%) consumed more than $10 \%$ TE of sugars from processed food except for white milk. A total of $32.1 \%$ of Koreans consumed more than $20 \mathrm{~g}$ of dietary sugars per day from beverages (data not shown).

\section{Relative risks of SSB overconsumption and population attributable} fractions to SSB overconsumption

Obesity, diabetes, cardiovascular diseases including hypertension, ischemic heart disease, and stroke, and dental caries were selected as diseases influenced by excessive sugars consumption (Table 1). In previous studies [2-6,22-27], the impact of excessive dietary sugars was mainly evaluated in terms of consumption of beverages, a major source of sugar. Disease-specific relative risks for consumption of $\geq 1$ serving a day of SSB were presented in Table 1.

Disease-specific PAF to overconsumption of dietary sugars from beverages ( $\geq 20 \mathrm{~g}$ of sugars from beverages) ranged from $3.11 \%$ for stroke to $9.05 \%$ for obesity and dental caries, respectively. For example, among a total of diabetic outpatients ( $n=2,500,933)$ and inpatients $(n=91,384)$ in 2015, 5.46\% (136,550 outpatients and 4,989 inpatients) were attributable to excessive SSB consumption. This would be preventable when

Table 1. Estimated effect of excessive consumption of sugar-sweetened beverages on specific diseases

\begin{tabular}{|c|c|c|c|c|c|}
\hline \multirow{2}{*}{\multicolumn{2}{|c|}{ Category (International classification of diseases- $10^{\text {th }}$ ) }} & \multirow{2}{*}{$\begin{array}{c}\text { Relative risk for } \geq 1 \\
\text { serving/day (reference) }\end{array}$} & \multirow{2}{*}{$\begin{array}{c}\text { Population attributable } \\
\text { fraction (\%) }\end{array}$} & \multicolumn{2}{|c|}{ Expected reduction } \\
\hline & & & & outpatients & inpatients \\
\hline Obesity & Obesity (E66) & $1.31[5]$ & 9.05 & 1,292 & 1 \\
\hline Diabetes & Diabetes (E10-E14) & $1.18[3,22-24]$ & 5.46 & 136,550 & 4,989 \\
\hline \multirow[t]{2}{*}{ Hypertension } & Primary hypertension (I10) & $1.12[2,25-27]$ & 3.71 & 215,412 & 1,868 \\
\hline & Other hypertensive diseases (I11-I15) & & & & \\
\hline \multirow[t]{2}{*}{ Ischemic heart disease } & Acute myocardial infarction (I21-I22) & $1.16[4,26]$ & 4.89 & 39,147 & 6,404 \\
\hline & Other ischemic heart diseases (120, 123-125) & & & & \\
\hline \multirow[t]{3}{*}{ Stroke } & Intracranial hemorrhage (160-162) & $1.10[26]$ & 3.11 & 15,295 & 4,172 \\
\hline & Cerebral infarction (163) & & & & \\
\hline & Stroke, not specified as hemorrhagic or infarction (164) & & & & \\
\hline Dental caries & Dental caries (K02) & $1.31[6]$ & 9.05 & 502,488 & 164 \\
\hline
\end{tabular}


Table 2. Estimated effect of excessive consumption of sugar-sweetened beverages on death from specific diseases

\begin{tabular}{|c|c|c|}
\hline Cause of death & $\begin{array}{c}\text { Population attributable } \\
\text { fraction (\%) }\end{array}$ & Expected reduction \\
\hline Diabetes & $2.5-8.0$ & 323.7 \\
\hline Men 20-44 yrs & 8.0 & 7.6 \\
\hline $45-64$ yrs & 5.4 & 69.7 \\
\hline$\geq 65$ yrs & 3.0 & 115.9 \\
\hline Women 20-44 yrs & 7.4 & 3.6 \\
\hline $45-64$ yrs & 5.1 & 19.8 \\
\hline$\geq 65$ yrs & 2.5 & 107.1 \\
\hline Cardiovascular disease & $0.1-0.5$ & 42.5 \\
\hline Men 20-44 yrs & 0.5 & 2.0 \\
\hline $45-64$ yrs & 0.3 & 9.3 \\
\hline$\geq 65$ yrs & 0.1 & 12.5 \\
\hline Women 20-44 yrs & 0.5 & 0.4 \\
\hline $45-64$ yrs & 0.3 & 2.2 \\
\hline$\geq 65$ yrs & 0.1 & 16.2 \\
\hline Cancer (specific sites) & 0.1 & 23.3 \\
\hline Men $20-44$ yrs & 0.1 & 0.3 \\
\hline $45-64$ yrs & 0.1 & 3.4 \\
\hline$\geq 65$ yrs & 0.1 & 8.2 \\
\hline Women 20-44 yrs & 0.1 & 0.5 \\
\hline $45-64$ yrs & 0.1 & 3.1 \\
\hline$\geq 65$ yrs & 0.1 & 7.8 \\
\hline
\end{tabular}

the prevalence of overconsumption (32.1\%) among the population decreased to $0 \%$. Among the outpatients, more than half were from dental caries, and two-thirds of inpatient results were from ischemic heart disease and diabetes.

Among a total of 273,265 deaths among adults aged $\geq 20$ years [30], 66,674 (24.4\%) died from diabetes, cardiovascular diseases, or specific-site cancers such as those in the esophagus, gallbladder, pancreas, colon, uterus, breast, and kidney (data not shown). The PAFs for cause-specific deaths were briefly presented in Table 2. A total of 389 deaths (229 in men, 160 in women) were estimated to be caused by SSB overconsumption. A considerable fraction of this reduction was from diabetes-specific deaths. Nearly $70 \%$ of the reduction in deaths were from a population aged 65 years or older, and the rest from an economically active population aged 20 to 64 years.
Table 4. Estimated savings from diminished early deaths caused by reducing sugar-sweetened beverages consumption (unit: 1,000 won)

\begin{tabular}{|c|c|c|c|c|}
\hline \multirow{2}{*}{ Cause of death } & \multicolumn{3}{|c|}{ Age groups } & \multirow{2}{*}{ Total } \\
\hline & 20-39 yrs & $40-59$ yrs & $\geq 60$ yrs & \\
\hline Diabetes & $4,550,836$ & $22,150,271$ & $5,581,654$ & $32,282,761$ \\
\hline Cardiovascular diseases & 931,008 & $3,334,407$ & 655,267 & $4,920,682$ \\
\hline Cancer (7 specific sites) & 191,190 & $1,271,955$ & 391,806 & $1,854,951$ \\
\hline Total & $5,673,034$ & $26,756,633$ & $6,628,727$ & $39,058,394$ \\
\hline
\end{tabular}

Socioeconomic burden due to SSB overconsumption

Cost savings due to reduced patients

The amounts of savings in direct and indirect costs were presented in Table 3. Among the outpatients, savings in medical care costs were 311 billion won and non-medical (transportation) cost savings were 39 billion won. Among inpatients, an estimated 105 billion won was saved in medical care costs and 40 billion won, a sum of 0.5 billion won (transportation costs) and 39.6 billion won (caregiver costs), were predicted to be saved in non-medical costs (data not shown). Thus, a total of 495 billion won of direct costs were estimated to be saved by preventing SSB overconsumption. Of direct cost savings, $80 \%$ was from a reduction in outpatients and the rest (20\%) from the costs associated with inpatients treatment. Among diseases, the reduction in diabetes or cardiovascular disease contributed substantially to cost savings by reducing dietary sugar intake.

Savings in indirect costs due to productivity loss were a total of 99 billion won, which consisted of 80 billion won from outpatient treatments and 19 billion won from inpatient treatments. A sum of 594 billion won was estimated to be saved by patients reducing sugary beverage overconsumption.

Cost savings due to reduced deaths

Cost savings derived from a reduction in deaths was estimated up to 39 billion won (Table 4). Most of the savings (83.0\%) came from reduction of death at under 60 years of age.

Total cost savings from preventing SSB overconsumption in Korea A total of 633 billion won was estimated as avoidable costs through preventing SSB overconsumption (Table 5). Fig. 1 shows the estimates of cost savings by age group. Socioeconomic burden caused by SSB overconsumption were considerably heavier in older age groups. Over half of the total amount was expected to be saved in those aged 60 years or older. In those under the age of 20 years, costs associated with

Table 3. Estimated savings from diminished patients due to sugar-sweetened beverages consumption reduction (unit: 1,000 won)

\begin{tabular}{|c|c|c|c|c|c|c|c|c|c|}
\hline \multirow{3}{*}{ Disease } & \multicolumn{5}{|c|}{ Direct cost } & \multicolumn{3}{|c|}{ Indirect cost } & \multirow{3}{*}{ Total } \\
\hline & \multicolumn{2}{|c|}{ Outpatients } & \multicolumn{2}{|c|}{ Inpatients } & \multirow[b]{2}{*}{ Total } & \multirow[b]{2}{*}{ Outpatients } & \multirow[b]{2}{*}{ Inpatients } & \multirow[b]{2}{*}{ Total } & \\
\hline & Medical cost & $\begin{array}{l}\text { Non-medical } \\
\text { cost }\end{array}$ & Medical cost & $\begin{array}{c}\text { Non-medical } \\
\text { cost }\end{array}$ & & & & & \\
\hline Obesity & 110,605 & 25,167 & 627 & 258 & 136,657 & 69,563 & 0 & 69,563 & 206,220 \\
\hline Diabetes & $106,347,268$ & $10,753,692$ & $15,431,592$ & $9,361,857$ & $141,894,409$ & $23,243,036$ & $4,521,031$ & $27,764,067$ & $169,658,476$ \\
\hline Hypertension & $123,248,877$ & $16,967,010$ & 7,134,501 & $5,827,312$ & $153,177,700$ & $36,478,031$ & $2,286,232$ & $38,764,263$ & $191,941,963$ \\
\hline Ischemic heart disease & $30,553,565$ & $1,616,057$ & $34,660,665$ & $3,539,113$ & $70,369,400$ & $3,007,164$ & $1,789,529$ & $4,796,693$ & $75,166,093$ \\
\hline Stroke & $14,669,244$ & 825,550 & $47,880,989$ & $21,358,660$ & $84,734,443$ & $1,453,674$ & $10,415,142$ & $11,868,816$ & $96,603,259$ \\
\hline Dental caries & $35,622,578$ & $8,884,399$ & 26,320 & 25,044 & $44,558,341$ & $15,399,435$ & 10,638 & $15,410,073$ & $59,968,414$ \\
\hline Total & $310,552,137$ & $39,071,875$ & $105,134,694$ & $40,112,244$ & $494,870,950$ & $79,650,903$ & $19,022,572$ & $98,673,475$ & $593,544,425$ \\
\hline
\end{tabular}


Table 5. Total cost-savings of sugar-sweetened beverages overconsumption by diseases and death from specific diseases (unit: 1,000 won)

\begin{tabular}{lrrr}
\hline & \multicolumn{2}{c}{ Benefits from reduced } & \multirow{2}{*}{ Total } \\
\cline { 2 - 3 } & \multicolumn{1}{c}{ patients } & \multicolumn{1}{c}{ deaths } & \\
\hline Obesity & 206,220 & 0 & 206,220 \\
Diabetes & $169,658,476$ & $32,282,761$ & $201,941,237$ \\
Cardiovascular diseases & $363,711,315$ & $4,920,682$ & $368,631,997$ \\
Dental caries & $59,968,414$ & 0 & $59,968,414$ \\
Cancers (7 site-specifics) & $\mathrm{N} / \mathrm{A}^{1)}$ & $1,854,951$ & $1,854,951$ \\
Total & $5 \ldots \ldots \ldots \ldots \ldots \ldots \ldots \ldots \ldots \ldots$ \\
\hline
\end{tabular}

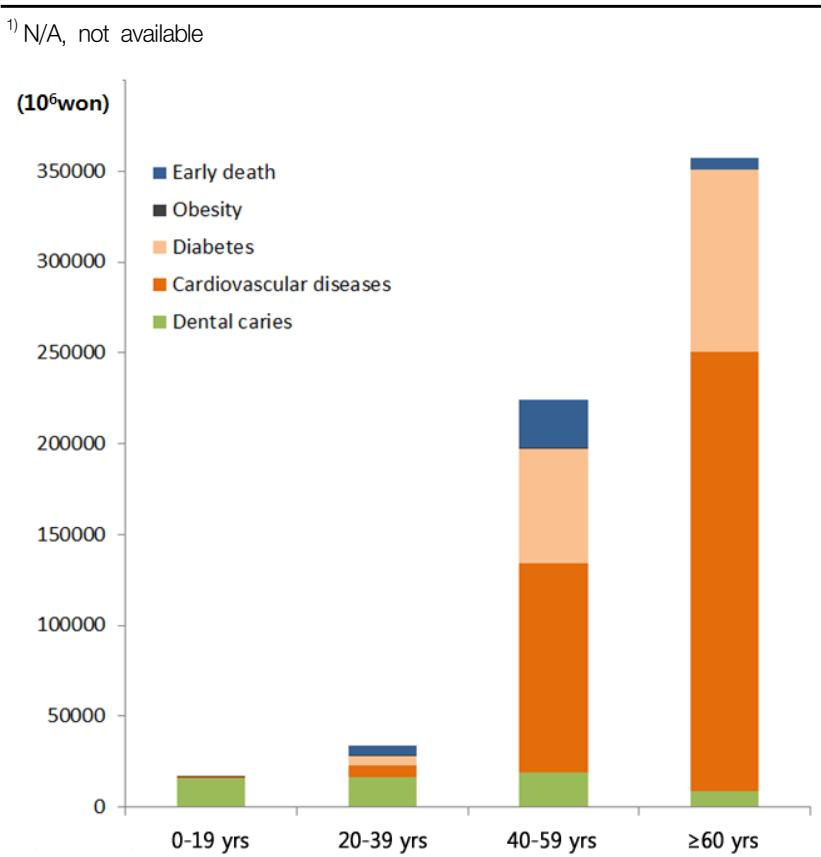

Fig. 1. Socioeconomic burden derived from sugar-sweetened beverages overconsumption according to age group

the treatment of dental caries accounted for a substantial portion ( $95.6 \%$ of 17 billion won, -16 billion won), and dental caries caused by SSB consumption was still a significant burden to those under 60 years of age, $48.1 \%$ of 34 billion won $(-16$ billion won) in 20-39 years and $8.4 \%$ of 224 billion won ( -19 billion won) in 40-59 years, respectively. In the older group, the socioeconomic burden was considerably heavier, especially associated with the treatment of diabetes and cardiovascular diseases.

\section{DISCUSSION}

Among Koreans aged 1 year or older, 32.1\% consumed more than $20 \mathrm{~g}$ of dietary sugar from beverages per day, which is equivalent to the amount of more than 1 serving of SSB. This amount of SSB consumption contributed to the development of multiple diseases, ranging from $3.11 \%$ for stroke to $9.05 \%$ for obesity and dental caries. The socioeconomic burden due to SSB overconsumption in Korea was estimated to be nearly 633 billion won.

In this study, dietary sugars overconsumption was considered as consuming more than 1 serving of SSB a day, which was defined as the intake of more than $20 \mathrm{~g}$ of sugar from beverages. The PAFs and the cost savings were estimated on the assumption that such a dietary problem was eliminated. Unlike most nutrients, dietary guidelines for sugars vary considerably across different countries in terms of the recommended amount and the types of sugar specified [8]. The WHO recommends reducing the intake of free sugar to less than to $10 \% \mathrm{TE}$, which is defined as mono- and disaccharides added to foods and beverages by the manufacturer, cook, or consumer, and sugars naturally present in honey, syrups, fruit juices, and fruit juice concentrates [39]. The European Food Safety Authority recommends reducing the daily intake of less than $10 \%$ TE from added sugar, only referring to those added during processing [40]. In the UK, the Scientific Advisory Committee of Nutrition recommends the intake of less than $10 \%$ TE from non-milk extrinsic sugars (NMES). The Institute of Medicine of the US suggests a relatively less strict level, with the intake of $25 \%$ TE from added sugar [41]. In Korea, the KNS recommends the intake of $10-20 \%$ TE from total sugar [19] and the MFDS suggests less than $10 \%$ TE of sugar from processed foods [38], respectively. Despite these differences, the intake of added sugars into raw food appears to be a common international issue. However, it is hard to divide sugar actually present in food into natural sugar and artificially-added categories because there is no chemical difference between these types, and thus few studies have reported the intake of added or free sugar in the population. For the same reason, a number of studies showing harmful effects of sugar overconsumption have usually focused on SSB consumption, rather than total or added sugar $[1,2,4,6,23,25,42,43]$. Therefore, we dealt with the problem of excessive sugar intake related to the overconsumption of sugar-containing beverages.

The socioeconomic burden magnitude of SSB consumption amounts to around $30 \%$ of the 2015 healthcare budget $(2,280$ billion won) for the Ministry of Health and Welfare [44] and corresponds roughly to 1.6 times of the budget (395 billion won) of the MFDS in the same year [45]. However, the estimate of the burden is considerably lower compared to that from excessive dietary sodium intake [31] as well as from smoking or alcohol intake [32], and even relatively lower compared to other countries [1]. There are some reasons for this difference. First, the prevalence of SSB overconsumption of Koreans is not as high as that of other health-related behaviors and other countries including Australia, Netherlands, and the United Kingdom, among others [17,39,46]. For instance, excessive sodium intake is a chronic public health problem in Korea, in which average intake is more than twice the recommended level and excessive consumption has been found in almost all individuals [46]. However, the average intake of dietary sugars is still within the recommended level and overconsumption of dietary sugar, as well as SSB, is relatively less prevalent in Korea [1,17], even though sugar intake is increasing continuously. Second, other health-related behaviors such as smoking, drinking, and excessive sodium intake have been considered major risk factors and their wide range of impact on health have long been investigated. However, evidence on the influence of sugar overconsumption has been growing and some results remain controversial $[43,47,48]$. In this study, the socioeconomic burden of SSB consumption was rigorously estimated on the basis of 
evidence which has been widely known and has few disputes. The estimate did not include the burden derived from some diseases under study. Thus, the actual benefits caused by reducing SSB consumption might be higher than the estimates in this study. In addition, sugar reduction could lead to priceless benefits such as improvement of health status and of quality of life, and even decrease health inequality.

This study has several strengths and limitations: This is the first study that estimates the PAFs to SSB overconsumption for diseases and deaths and its socioeconomic burden for Koreans. This result provides information that helps health professionals and policy makers to prioritize and allocate their resources, and also to implement programs for healthier dietary habits. However, the cost savings in this study may be underestimated for the several reasons. First, the cost savings did not include any reduction in informal care expenses. Second, if SSB overconsumption is prevented, reducing the severity of disease, it may result in some benefits such as improvement of the quality of life for patients. However, we could not consider any benefits due to a reduction in the severity of diseases. Third, estimates of cost savings included only socioeconomic benefits from some diseases and specific-cause deaths considered in this study, aside from other diseases under study. Finally, we estimated the PAF of SSB overconsumption using the relative risks of SSB consumption for morbidity and mortality, much information was merely available from foreign studies. If it is possible to apply the RR of Korean, more accurate estimation can be done.

In conclusion, sugar overconsumption causes a considerable public burden, although the cost estimates do not include any informal expenditures. Information on this socioeconomic burden helps health professionals and policy makers to create and to implement programs for reducing sugar consumption.

\section{CONFLICT OF INTEREST}

The authors declare no potential conflicts of interests.

\section{ORCID}

Jee-Seon Shim: https://orcid.org/0000-0002-8671-3153

Nam Hoon Kang: https://orcid.org/0000-0002-0877-8373

Jung Sug Lee: https://orcid.org/0000-0001-8738-6409

Ki Nam Kim: https://orcid.org/0000-0002-9485-567X

Hae Kyung Chung: https://orcid.org/0000-0002-1002-2399

Hae Rang Chung: https://orcid.org/0000-0002-1026-3512

Hung-Ju Kim: https://orcid.org/0000-0002-2244-1806

Yoon-Sook Ahn: https://orcid.org/0000-0001-7819-9505

Moon-Jeong Chang: https://orcid.org/0000-0002-2880-6458

\section{REFERENCES}

1. Singh GM, Micha R, Khatibzadeh S, Lim S, Ezzati M, Mozaffarian D; Global Burden of Diseases Nutrition and Chronic Diseases Expert Group (NutriCoDE). Estimated global, regional, and national disease burdens related to sugar-sweetened beverage consumption in 2010. Circulation 2015;132:639-66.

2. Jayalath VH, de Souza RJ, Ha V, Mirrahimi A, Blanco-Mejia S, Di Buono $M$, Jenkins AL, Leiter LA, Wolever TM, Beyene J, Kendall CW,
Jenkins DJ, Sievenpiper JL. Sugar-sweetened beverage consumption and incident hypertension: a systematic review and meta-analysis of prospective cohorts. Am J Clin Nutr 2015;102:914-21.

3. Imamura F, O'Connor L, Ye Z, Mursu J, Hayashino Y, Bhupathiraju $\mathrm{SN}$, Forouhi NG. Consumption of sugar sweetened beverages, artificially sweetened beverages, and fruit juice and incidence of type 2 diabetes: systematic review, meta-analysis, and estimation of population attributable fraction. BMJ 2015;351:h3576.

4. Huang C, Huang J, Tian Y, Yang X, Gu D. Sugar sweetened beverages consumption and risk of coronary heart disease: a meta-analysis of prospective studies. Atherosclerosis 2014;234:11-6.

5. Dhingra R, Sullivan L, Jacques PF, Wang TJ, Fox CS, Meigs JB, D'Agostino RB, Gaziano JM, Vasan RS. Soft drink consumption and risk of developing cardiometabolic risk factors and the metabolic syndrome in middle-aged adults in the community. Circulation 2007;116:480-8.

6. Bernabé E, Vehkalahti MM, Sheiham A, Aromaa A, Suominen AL. Sugar-sweetened beverages and dental caries in adults: a 4-year prospective study. J Dent 2014;42:952-8.

7. World Health Organization. Guideline: Sugars Intake for Adults and Children. Geneva: World Health Organization; 2015.

8. Hess J, Latulippe ME, Ayoob K, Slavin J. The confusing world of dietary sugars: definitions, intakes, food sources and international dietary recommendations. Food Funct 2012;3:477-86.

9. Long MW, Gortmaker SL, Ward Z, Resch SC, Moodie ML, Sacks G, Swinburn BA, Carter RC, Claire Wang Y. Cost effectiveness of a sugar-sweetened beverage excise tax in the U.S. Am J Prev Med 2015;49:112-23.

10. Colchero MA, Popkin BM, Rivera JA, Ng SW. Beverage purchases from stores in Mexico under the excise tax on sugar sweetened beverages: observational study. BMJ 2016;352:h6704.

11. Kelly B, Hughes C, Chapman K, Louie JC, Dixon H, Crawford J, King $\mathrm{L}$, Daube $\mathrm{M}$, Slevin T. Consumer testing of the acceptability and effectiveness of front-of-pack food labelling systems for the Australian grocery market. Health Promot Int 2009;24:120-9.

12. Capacci S, Mazzocchi M, Shankar B. Breaking habits: the effect of the french vending machine ban on school snacking and sugar intakes. J Policy Anal Manage 2018;37:88-111.

13. Wrieden WL, Levy LB. 'Change4Life Smart Swaps': quasiexperimental evaluation of a natural experiment. Public Health Nutr 2016;19:2388-92.

14. Barragan NC, Noller AJ, Robles B, Gase LN, Leighs MS, Bogert S, Simon PA, Kuo T. The "sugar pack" health marketing campaign in Los Angeles County, 2011-2012. Health Promot Pract 2014;15: 208-16.

15. Øverby NC, Klepp Kl, Bere E. Introduction of a school fruit program is associated with reduced frequency of consumption of unhealthy snacks. Am J Clin Nutr 2012;96:1100-3.

16. Lee HS, Kwon SO, Yon M, Kim D, Lee JY, Nam J, Park SJ, Yeon JY, Lee SK, Lee HY, Kwon OS, Kim Cl. Dietary total sugar intake of Koreans: based on the Korea National Health and Nutrition Examination Survey (KNHANES), 2008-2011. J Nutr Health 2014;47: 268-76.

17. Azaïs-Braesco V, Sluik D, Maillot M, Kok F, Moreno LA. A review of total \& added sugar intakes and dietary sources in Europe. Nutr J 2017;16:6.

18. Newens KJ, Walton J. A review of sugar consumption from nationally representative dietary surveys across the world. J Hum 
Nutr Diet 2016;29:225-40.

19. Korean Nutrition Society, Ministry of Health and Welfare. Dietary Reference Intakes for Koreans 2015. Seoul: The Korean Nutrition Society; 2015.

20. Jung J. Action plan for sugars reduction. Food Sci Ind 2016;49:12-6.

21. Korea Health Industry Development Institute. Sugar Database Compilation for Commonly Consumed Foods 2015. Cheongju: Korea Health Industry Development Institute; 2015.

22. Kahn R, Sievenpiper JL. Dietary sugar and body weight: have we reached a crisis in the epidemic of obesity and diabetes?: we have, but the pox on sugar is overwrought and overworked. Diabetes Care 2014;37:957-62.

23. Malik VS, Popkin BM, Bray GA, Després JP, Willett WC, Hu FB. Sugar-sweetened beverages and risk of metabolic syndrome and type 2 diabetes: a meta-analysis. Diabetes Care 2010;33:2477-83.

24. Greenwood DC, Threapleton DE, Evans CE, Cleghorn CL, Nykjaer C, Woodhead C, Burley VJ. Association between sugar-sweetened and artificially sweetened soft drinks and type 2 diabetes: systematic review and dose-response meta-analysis of prospective studies. Br J Nutr 2014;112:725-34.

25. Cheungpasitporn W, Thongprayoon C, Edmonds PJ, Srivali N, Ungprasert $\mathrm{P}$, Kittanamongkolchai W, Erickson SB. Sugar and artificially sweetened soda consumption linked to hypertension: a systematic review and meta-analysis. Clin Exp Hypertens 2015;37: 587-93.

26. Xi B, Huang Y, Reilly KH, Li S, Zheng R, Barrio-Lopez MT, Martinez-Gonzalez MA, Zhou D. Sugar-sweetened beverages and risk of hypertension and CVD: a dose-response meta-analysis. $\mathrm{Br}$ J Nutr 2015;113:709-17.

27. Kim Y, Je Y. Prospective association of sugar-sweetened and artificially sweetened beverage intake with risk of hypertension. Arch Cardiovasc Dis 2016;109:242-53.

28. Gordis L. Epidemiology, 3rd ed. Philadelphia, PA: Elsevier Saunders; 2004.

29. Health Insurance Review and Assessment Service, National Health Insurance Service (KR). 2015 National Health Insurance Statistical Yearbook. Wonju: National Health Insurance Service; 2016.

30. Statistics Korea. Annual Report on the Cause of Death Statistics. Daejeon: Statistics Korea; 2016.

31. Lee C, Kim DI, Hong J, Koh E, Kang BW, Kim JW, Park HK, Kim $\mathrm{Cl}$. Cost-benefit analysis of sodium intake reduction policy in Korea. Korean J Community Nutr 2012;17:341-52.

32. National Health Insurance Service (KR). The Socioeconomic Effects of Major Health Risk Factors and the Evaluation of Effects of Their Regulation Policies. Wonju: National Health Insurance Service; 2015.

33. National Health Insurance Corporation, Health Insurance Review and Assessment Service (KR). 2015 Survey on Medical Expenditure of Patients Insured by National Health Insurance. Wonju: National Health Insurance Service; 2016.

34. Ministry of Health and Welfare, Korea Institute for Health and Social Affairs. The Third Korea National Health and Nutrition Examination Survey (KNHANES III). Cheongju: Ministry of Health and Welfare; 2005.

35. Ministry of Employment and Labor (KR). 2015 Survey Report on Labor Conditions by Employment Type. Sejong: Ministry of Employment and Labor; 2016.

36. Statistics Korea. 2015 Economically Active Population Survey.
Daejeon: Statistics Korea; 2016.

37. Korea Centers for Disease Control and Prevention. Guide Book for Using the Data from Korea National Health and Nutrition Examination Survey 2013-2015. Cheongju: Korea Centers for Disease Control and Prevention; 2017.

38. Ministry of Food and Drug Safety (KR). Comprehensive Plan for Reduction of Sugars 2016. Cheongju: Ministry of Food and Drug Safety; 2016.

39. Wittekind A, Walton J. Worldwide trends in dietary sugars intake. Nutr Res Rev 2014;27:330-45.

40. European Food Safety Authority. Scientific opinion on dietary reference values for carbohydrates and dietary fibre. EFSA J 2010;8: 1462-539.

41. Institute of Medicine. Dietary Reference Intakes for Energy, Carbohydrate, Fiber, Fat, Fatty Acids, Cholesterol, Protein, and Amino Acids. Washington, D.C.: The National Academies Press; 2002.

42. Gibson S. Sugar-sweetened soft drinks and obesity: a systematic review of the evidence from observational studies and interventions. Nutr Res Rev 2008;21:134-47.

43. Navarrete-Muñoz EM, Wark PA, Romaguera $D$, Bhoo-Pathy $N$, Michaud D, Molina-Montes E, Tjønneland A, Olsen A, Overvad K, Boutron-Ruault MC, Clavel-Chapelon F, Fagherazzi G, Katzke VA, Kühn T, Steffen A, Trichopoulou A, Klinaki E, Papatesta EM, Masala G, Krogh V, Tumino R, Naccarati A, Mattiello A, Peeters PH, Rylander C, Parr CL, Skeie G, Weiderpass E, Quirós JR, Duell EJ, Dorronsoro M, Huerta JM, Ardanaz E, Wareham N, Khaw KT, Travis RC, Key T, Stepien M Freisling H, Riboli E, Bueno-de-Mesquita HB. Sweetbeverage consumption and risk of pancreatic cancer in the European Prospective Investigation into Cancer and Nutrition (EPIC). Am J Clin Nutr 2016;104:760-8.

44. Ministry of Health and Welfare (KR). 2015 Budget of the Ministry of Health and Welfare [Internet]. Cheongju: Ministry of Health and Welfare; 2014 [cited 2018 March 2]. Available from: http://www. mohw.go.kr/react/al/sal0301vw.jsp?PAR_MENU_ID=04\&MENU_ID= 0403\&CONT_SEQ=305131\&page $=1$.

45. Ministry of Food and Drug Safety (KR). 2015 Overview of budget of the Ministry of Food and Drug Safety [Internet]. Cheongju: Ministry of Food and Drug Safety; 2014 [cited 2018 March 2]. Available from: http://www.mfds.go.kr/index.do?mid=636\&pageNo $=1 \& \mathrm{cmd}=\mathrm{v} \& \mathrm{seq}=47618$.

46. Korea Centers for Diseases Control and Prevention. 2015 Statistics on Health-Related Behaviors and Chronic Diseases: the 6th Korea National Health and Nutrition Survey and 11th Korean Youth Risk Behavior Survey. Cheongju: Ministry of Health and Welfare; 2016.

47. Larsson SC, Bergkvist L, Wolk A. Consumption of sugar and sugar-sweetened foods and the risk of pancreatic cancer in a prospective study. Am J Clin Nutr 2006;84:1171-6.

48. Genkinger JM, Li R, Spiegelman D, Anderson KE, Albanes $D$, Bergkvist $L$, Bernstein L, Black A, van den Brandt PA, English DR, Freudenheim JL, Fuchs CS, Giles GG, Giovannucci E, Goldbohm RA, Horn-Ross PL, Jacobs EJ, Koushik A, Männistö $S$, Marshall JR, Miller $A B$, Patel AV, Robien $K$, Rohan TE, Schairer C, Stolzenberg-Solomon R, Wolk A, Ziegler RG, Smith-Warner SA. Coffee, tea, and sugar-sweetened carbonated soft drink intake and pancreatic cancer risk: a pooled analysis of 14 cohort studies. Cancer Epidemiol Biomarkers Prev 2012;21:305-18. 